\title{
A New Methodology for Hesitant Fuzzy Emergency Decision Making with Unknown Weight Information
}

\author{
Xiaodi Liu $\mathbb{D}^{1},{ }^{1}$ Zengwen Wang $\mathbb{D}^{2},{ }^{2}$ and Shitao Zhang $^{1}$ \\ ${ }^{1}$ School of Mathematics and Physics, Anhui University of Technology, Ma'anshan, Anhui 243002, China \\ ${ }^{2}$ Researching Center of Social Security, Wuhan University, Wuhan, Hubei 430072, China \\ Correspondence should be addressed to Zengwen Wang; wzwnjing@163.com
}

Received 11 June 2018; Accepted 6 September 2018; Published 5 November 2018

Academic Editor: Yongping Pan

Copyright (c) 2018 Xiaodi Liu et al. This is an open access article distributed under the Creative Commons Attribution License, which permits unrestricted use, distribution, and reproduction in any medium, provided the original work is properly cited.

\begin{abstract}
Once an emergency event occurs, effective emergency measures should be taken. It is known that the emergency event possesses characteristics of limited time and information, harmfulness, and uncertainty, and the decision makers are often bounded rational under uncertainty and risk. This paper presents a novel approach to emergency decision making with hesitant fuzzy information, which takes regret aversion of the decision makers into account. Firstly, based on the idea of the water-filling theory in the field of wireless communications, a mathematical programming model that can convert the attribute values into a compatible scale and eliminate the influence of different physical dimensions is constructed to determine the attribute weights. Then, a group satisfaction degree function is introduced into the regret theory to depict the psychological behaviors of the decision makers, based on which the perceived utility value function of alternative is constructed. The total perceived utility values of alternatives can be computed, and the ranking order of alternatives is obtained. Finally, a case study on a fire and explosion accident is given to illustrate the application of the proposed method. Besides that, the comparisons show the feasibility and superiority of the proposed method.
\end{abstract}

\section{Introduction}

In the 21st century, along with the rapid process of economic globalization and integration, human beings are faced with various crises, such as the September 11 terrorist attacks in 2001, Catalina hurricane in 2005, Wenchuan earthquake in 2008, and explosion accident at Port Group in Tianjin in 2015, which could cause serious economic loss, threaten people's living conditions, and lead to social panic. When an emergency event happens, the decision makers or department of emergency management should formulate plans or select an effective emergency alternative to prevent further deterioration of the situation. It is a subject for the field of emergent management to make quick and reasonable decisions. As an important part of emergency management, the emergency decision making has become an important job of many countries and a focus of research in academic circles.

The behavioral experiments demonstrate that people are often bounded rational under uncertainty and risk [1-3].
Therefore, the psychological behaviors of people should be considered in the actual decision processes. It is known that a noteworthy feature of the emergency response is timeliness, and there also exists much unknown and uncertain information in emergency response. In this situation, people are usually bounded rational rather than complete rational when making decisions $[4,5]$. Therefore, it is necessary to develop decision methods considering human behaviors so as to provide effective ways for people in emergency response. Liu et al. [6] put forward a risk decision method based on the cumulative prospect theory to handle the risk decision making problem in emergency response. Wang et al. [5] presented an interval dynamic reference point method based on the prospect theory for emergency decision making. Schmidt and Zank [7] characterized the conditions for risk aversion in cumulative prospect theory and presented an index for measuring the degree of loss aversion. Liu et al. [8] put forward an approach based on the prospect theory to risk decision making problems with interval probability. However, there are some shortcomings when adopting the 
prospect theory or cumulative prospect theory to solve the decision making problems [9]. Nwogugu [9] stated that the prospect theory and cumulative prospect theory failed to explain many aspects of decision making and risk. According to neurobiology, Nwogugu [9] demonstrated that the natural mental process of human beings could lead to decision making patterns, which differ from those predicted by and implied in the prospect theory and cumulative prospect theory. In addition, Nagarajan and Shechter [10] pointed out that the consistent empirical findings could not be explained by the prospect theory. Hence, it is necessary to develop more realistic decision models. To portray intuitive judgments more simply and consistently, Bell [11] and Loomes and Sugden [12] proposed the regret theory independently, where rejoice and regret factors were introduced when computing the utility values. Considering that the original version of the regret theory was limited to pairwise choices, Quiggin [13] extended it to a more general form that the optimal alternative can be selected from multiple alternatives. Then, the regret theory is modified to accommodate the impact of outcome feedback on anticipated regretaversion [14]. Bleichrodt et al. [15] proposed an approach to make the regret theory quantitatively observable. Until now, the regret theory has been applied to many areas, such as currency hedging decisions [16], portfolio selection [17], and the production decision of the competitive [18]. Moreover, some researchers have attempted to introduce the regret theory to the multiple-attribute decision making process. Zhang et al. [19] presented an approach based on the regret theory to deal with the risky multiple attribute decision making problems, where the attribute values are in the form of interval numbers. Zhang et al. [20] studied the fuzzy multiple-attribute decision group decision making problem with incomplete weight information and developed a novel group decision making method considering regret aversion of the decision makers. Lin et al. [21] applied the regret theory to solve the matching decision making problem within the context of hesitant fuzzy environment. Zhou et al. [22] proposed a grey stochastic decision making method based on the regret theory and TOPSIS. Yang and Wang [23] presented a decision making method based on the regret theory and stochastic multicriteria acceptability analysis within the context of discrete $Z$-number.

It is known that uncertainty widely exists in the complex realities [24]. Meanwhile, due to the fuzziness of human thought as well as the complexity of the external environment, it is difficult for the decision makers to give precise preferences. Thus, it is necessary to develop novel tools to model the uncertainty. As an extension of fuzzy set [25], hesitant fuzzy set (HFS) contains all the possible membership degrees in a set and is an effective tool in simulating the situation where people are irresolute and hesitant for one thing or another [26]. For example, when an emergency event happens, some effective measures should be taken to minimize the losses. The process of selecting the alternatives can be interpreted as emergency decision making, which requires multiple experts with different professional backgrounds to make judgments. Usually, views are divided and it is difficult to reach an agreement. At this point, hesitant fuzzy sets will be useful to deal with the situation. Because of its strong ability to depict fuzziness and reserve original information, hesitant fuzzy sets have drawn the attention of scholars [27-41]. Zhang et al. [42] and Ren et al. [4] proposed hesitant fuzzy emergency decision making methods based on the prospect theory, respectively. Based on the above analysis, we can find that the hesitant fuzzy set theory and applications have obtained rapid advances. However, the existing research on HFS is mainly focused on the rational decision theory. Although the prospect theory has been employed to deal with the hesitant fuzzy emergency decision making problems [4, 42], there exist some shortcomings as mentioned above. Besides, it needs the decision makers to specify reference points and the calculation functions contain more parameters [22], which would increase the uncertainty of the decision results. Note that the psychology of regret aversion is typically implied when making decisions. It is thus necessary to quantitatively express the regret aversion of the decision makers in a hesitant fuzzy environment. In addition, attribute weights play an important part in multiple-attribute decision making (MADM). Therefore, it is one of the core issues to identify the attribute weights in the decision making process. Many researchers have focused on the determination of attribute weights. However, few efforts have been made to remove the impact of attribute magnitude and dimension when determining the attribute weights. Since the physical dimensions of attributes are different, it is necessary to develop a more reasonable and effective approach for determining the attribute weights. For these reasons, we will present in this paper a novel approach based on the regret theory to deal with the hesitant fuzzy emergency decision making problems. To do this, we must tackle the following three challenges: (1) how to calculate the perceived utility values of alternatives and express the regret aversion of the decision makers within the context of a hesitant fuzzy environment, (2) how to determine the attribute weights reasonably where the physical dimensions of attributes are different, and (3) how to establish an appropriate method for hesitant fuzzy emergency decision making. Due to lack of knowledge, complexity, and so on, it is common to assume that the attribute weights are sometimes unknown. Therefore, it is an important issue, which is worth discussing thoroughly, to know how to deal with the hesitant fuzzy emergency decision making problems with unknown weight information for considering the psychological behaviors of decision makers.

To do this, the remainder of the paper is organized as follows. Section 2 reviews some basic concepts. In Section 3, we describe the hesitant fuzzy emergency decision making problems and put forward a group satisfaction degree formula. With the aid of the water-filling theory, we present an approach to determine the attribute weights, and then an approach to hesitant fuzzy emergency decision making based on the regret theory is presented. In Section 4, a real case on emergency decision making is provided to demonstrate the application of the proposed method, and the comparisons with other methods are also conducted. Conclusions are offered in Section 5. 


\section{Preliminaries}

2.1. Hesitant Fuzzy Sets. As a generalization of fuzzy set, HFS can be utilized to model the hesitancy effectively when people are irresolute all the way and cannot reach an agreement. In the following, some basic concepts related to HFS are given.

Definition 1 (see [26]). Assume that $X$ is a reference set. An HFS on $X$ is defined in terms of a function that when applied to $X$ returns a subset of $[0,1]$.

$\mathrm{Xia}$ and $\mathrm{Xu}$ [38] adopted the following mathematical symbol to express the HFS:

$$
E=\left\{\left\langle x, h_{E}(x)\right\rangle \mid x \in X\right\}
$$

where $h_{E}(x)$ is a set of several values in $[0,1] . h_{E}(x)$ is called as a hesitant fuzzy element (HFE), which denotes the possible membership degrees of $x \in X$ to the set $E$.

Then, some new operations over HFEs are defined as follows.

Definition 2 (see [38]). Let $h, h_{1}, h_{2}$ be three HFEs, then

(1) $h^{\lambda}=\bigcup_{\gamma \in h}\left\{\gamma^{\lambda}\right\}, \lambda>0$

(2) $\lambda h=\bigcup_{\gamma \in h}\left\{1-(1-\gamma)^{\lambda}\right\}, \lambda>0$

(3) $h_{1} \oplus h_{2}=\bigcup_{\gamma_{1} \in h_{1}, \gamma_{2} \in h_{2}}\left\{\gamma_{1}+\gamma_{2}-\gamma_{1} \gamma_{2}\right\}$

(4) $h_{1} \otimes h_{2}=\bigcup_{\gamma_{1} \in h_{1}, \gamma_{2} \in h_{2}}\left\{\gamma_{1} \gamma_{2}\right\}$

(5) $\left(h^{c}\right)^{\lambda}=(\lambda h)^{c}$

(6) $\lambda\left(h^{c}\right)=\left(h^{\lambda}\right)^{c}$

(7) $h_{1}^{c} \oplus h_{2}^{c}=\left(h_{1} \otimes h_{2}\right)^{c}$

(8) $h_{1}^{c} \otimes h_{2}^{c}=\left(h_{1} \oplus h_{2}\right)^{c}$

Here, $h_{i j}^{c}$ denotes the complement of $h_{i j}$, such that $h_{i j}^{c}=\bigcup_{\gamma \in h_{i j}}\{1-\gamma\}$.

Based on the operations above, Xia and $\mathrm{Xu}$ [38] proposed the hesitant fuzzy weighted averaging (HFWA) operator.

Definition 3. Let $h_{j}(j=1,2, \cdots, n)$ be a collection of HFEs. A HFWA operator is a mapping $H^{n} \longrightarrow H$ such that

$$
\begin{aligned}
\operatorname{HFWA}_{w}\left(h_{1}, h_{2}, \cdots, h_{n}\right)= & \underset{j=1}{\oplus}\left(w_{j} h_{j}\right) \\
= & \bigcup_{\gamma_{1} \in h_{1}, \gamma_{2} \in h_{2}, \ldots, \gamma_{n} \in h_{n}} \\
& \cdot\left\{1-\prod_{j=1}^{n}\left(1-\gamma_{j}\right)^{w_{j}}\right\},
\end{aligned}
$$

where $w=\left(w_{1}, w_{2}, \cdots, w_{n}\right)^{T}$ is the weighting vector of $h_{j}(j=1,2, \cdots, n)$ with $w_{j} \in[0,1]$ and $\sum_{j=1}^{n} w_{j}=1$.
In order to compare the HFEs, a series of ranking methods are presented $[38,43]$. The following comparison laws possess the advantage of less calculation, and it is easy to conduct.

Definition 4 (see [38]). Assume that $h$ is a HFE. Then,

$$
s(h)=\frac{1}{l} \sum_{\gamma \in h} \gamma
$$

is defined as the score function of $h$, where $l$ denotes the number of the values in $h$. For any two HFEs $h_{1}$ and $h_{2}$, if $s\left(h_{1}\right)>s\left(h_{2}\right)$, then $h_{1}>h_{2}$; if $s\left(h_{1}\right)=s\left(h_{2}\right)$, then $h_{1}=h_{2}$.

Then, the mean of HFS $E$ is defined as below.

Definition 5 (see [44]). Let $X$ be a reference set, and assume that $E=\left\{\left\langle x_{j}, h_{E}\left(x_{j}\right)\right\rangle \mid x_{j} \in X, j=1,2, \cdots, n\right\}$ is an HFS on $X$. The mean of HFS $E$ is defined as below:

$$
s(E)=\frac{1}{n} \sum_{j=1}^{n} s\left(h_{E}\left(x_{j}\right)\right)=\frac{1}{n} \sum_{j=1}^{n}\left(\frac{1}{l_{j}} \sum_{\gamma_{j} \in h_{E}\left(x_{j}\right)} \gamma_{j}\right),
$$

where $l_{j}$ represents the number of the values in $h_{E}\left(x_{j}\right)$.

Liu et al. [45] defined the standard deviation of HFS E.

Definition 6. Let $X$ be a reference set, and assume that $E=\left\{\left\langle x_{j}, h_{E}\left(x_{j}\right)\right\rangle \mid x_{j} \in X, j=1,2, \cdots, n\right\}$ is an HFS on $X$. Then,

$$
\sigma(E)=\sqrt{\frac{1}{n} \sum_{j=1}^{n}\left(s\left(h_{E}\left(x_{j}\right)\right)-s(E)\right)^{2}}
$$

is called the standard deviation of HFS $E$, where $s\left(h_{E}\left(x_{j}\right)\right)$ and $s(E)$ denote the score function of HFE $h_{E}\left(x_{j}\right)$ and the mean of HFS $E$, respectively. Accordingly, the standard 132\#deviation of HFE $h_{E}\left(x_{j}\right)$ can be obtained as follows:

$$
\sigma\left(h_{E}\left(x_{j}\right)\right)=\sqrt{\frac{1}{l_{j}} \sum_{\gamma_{j} \in h_{E}\left(x_{j}\right)}\left(\gamma_{j}-s\left(h_{E}\left(x_{j}\right)\right)\right)^{2}} .
$$

2.2. Regret Theory. As one of the most important behavioral decision theories, the regret theory was put forward independently by Loomes and Sugden [12] and Bell [11]. They imported regret and rejoice factors into the calculation of utility value. In the process of decision making, people's psychological behavior, such as regret aversion, can be quantified [15]. According to the regret theory, people rejoice that the selected alternative will bring better results than others; otherwise, they will feel regret.

Definition 7. Let $x_{1}$ and $x_{2}$ be the results which are obtained through choosing alternatives $A_{1}$ and $A_{2}$, respectively, 
then the perceived utility for alternative $A_{1}$ can be defined as below:

$$
u\left(x_{1}, x_{2}\right)=v\left(x_{1}\right)+R\left(v\left(x_{1}\right)-v\left(x_{2}\right)\right) .
$$

Here, $v(\cdot)$ denotes the utility function with $v^{\prime}(\cdot)>0$ and $v^{\prime \prime}(\cdot)<0 . R(\cdot)$ represents the regret-rejoice function with $R(0)=0, R^{\prime}(\cdot)>0$ and $R^{\prime \prime}(\cdot)<0$. Moreover, $\Delta v=$ $v\left(x_{1}\right)-v\left(x_{2}\right)$ denotes the difference between two utility values of alternatives $A_{1}$ and $A_{2}$. When $R(\Delta v)>0$, people will rejoice at the selected alternative; otherwise, they will feel regret.

In general, the power function $v(x)=x^{\alpha}(\alpha \in(0,1))$ is adopted to quantify the utility value, where $\alpha$ denotes the risk aversion coefficient of the decision maker. Here, the smaller the parameter $\alpha$ is, the greater the risk aversion of the decision maker is. The effect of parameter $\alpha$ on utility function $v(x)$ is shown in Figure 1.

In addition, $R(\cdot)$ is strictly increasing and concave and can be represented by the following function:

$$
R(x)=1-\exp (-\delta \cdot x)
$$

where $\delta \in[0,+\infty)$ denotes the regret aversion coefficient. Generally, the larger the parameter $\delta$ is, the greater the regret aversion of the decision maker is. The effect of parameter $\delta$ on regret-rejoice function $R(x)$ is shown in Figure 2.

In practice, we often face the situation that the optimal alternative should be selected from multiple alternatives $A_{i}(i=1,2, \cdots, m)$. Then, the regret theory was extended to handle this situation [13]. Let $x_{i}(i=1,2, \cdots, m)$ be the results of alternatives $A_{i}(i=1,2, \cdots, m)$, respectively. The perceived utility for alternative $A_{i}$ can be defined as below:

$$
u_{i}=v\left(x_{i}\right)+R\left(v\left(x_{i}\right)-v\left(x^{*}\right)\right) .
$$

Here, $\quad x^{*}=\max _{1 \leq i \leq m}\left\{x_{i}\right\} \quad$ and $\quad R\left(v\left(x_{i}\right)-v\left(x^{*}\right)\right) \leq 0$. $R\left(v\left(x_{i}\right)-v\left(x^{*}\right)\right)$ represents the regret value, which implies that people will feel regret after choosing alternative $A_{i}$ instead of $x^{*}$. As a matter of fact, the regret theory shows that the classical utility function is modified by incorporating a regret-rejoice term. Therefore, the perceived utility value of a decision maker for an alternative consists of two components: the utility value and the regret-rejoice value.

\section{Hesitant Fuzzy Emergency Decision Making Method}

In this section, a hesitant fuzzy emergency decision making problem with unknown attribute weights is investigated. The regret theory and water-filling theory are introduced into the field of emergency decision making with hesitant fuzzy information. Considering that the physical dimensions of decision attributes are different, we adopt the waterfilling theory in the field of wireless communications to determine the attribute weights. Also, based on the above, the emergency decision making process is given.

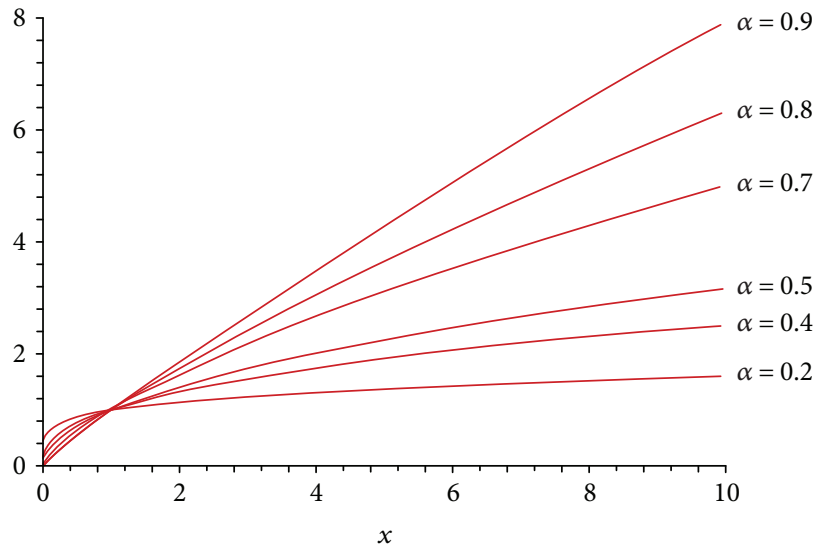

FIGURE 1: The graph of utility function $v(x)=x^{a}$.

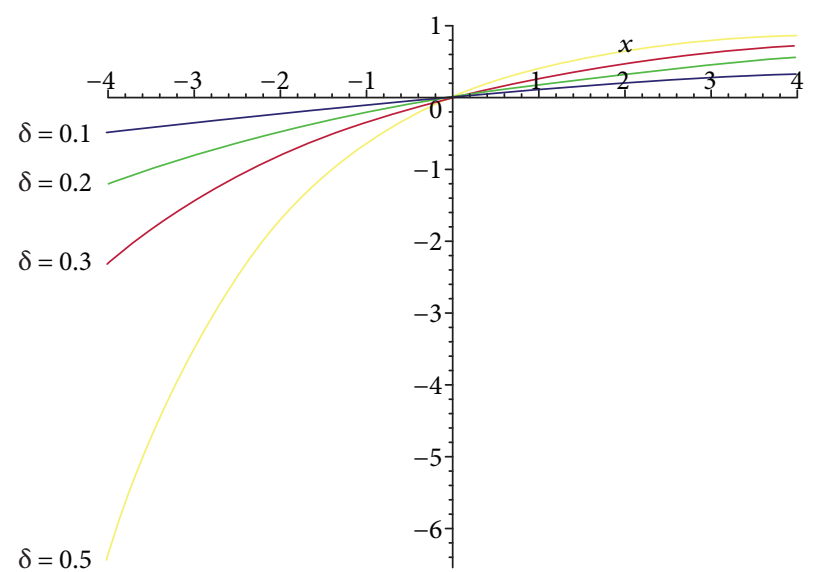

Figure 2: The graph of the regret-rejoice function $R(x)=1-$ $\exp (-\delta \cdot x)$

3.1. Problem Description. With the development of society, disasters occur frequently and have brought about serious loss to economic development. Emergency decision making plays an important part in dealing with emergency problems. This paper focuses on a hesitant fuzzy emergency decision making problem with attribute weights completely unknown.

Let $\left\{Y_{1}, Y_{2}, \cdots, Y_{m}\right\}$ be the set of alternatives, and $\left\{C_{1}, C_{2}, \cdots, C_{n}\right\}$ be the set of attributes whose weight vector is $W=\left(w_{1}, w_{2}, \cdots, w_{n}\right)^{T}$ with $\sum_{j=1}^{n} w_{j}=1$ and $0 \leq w_{j} \leq$ $1(j=1,2, \cdots, n)$. In the emergency decision making problems, $\phi$ experts $\Delta_{k}(k=1,2, \cdots, \phi)$ are determined. Usually, information on attribute weights is unknown due to the vagueness and uncertainty of the decision problems. Suppose that the experts evaluate $m$ alternatives $Y_{i}(i=1,2, \cdots, m)$ with respect to $n$ attributes $C_{j}(j=1,2, \cdots, n)$. Assume that $D_{k}=\left(h_{i j}^{k}\right)_{m \times n}(i=1,2, \cdots, m, j=1,2, \cdots, n, k=1,2, \cdots, \phi) \quad$ is the hesitant fuzzy decision matrix. Here, $h_{i j}^{k}$ is a HFE that denotes the membership degree of the alternative $Y_{i}$ satisfying the attribute $C_{j}$ given by the $k$ th expert.

Usually, the attributes $C_{j}(j=1,2, \cdots, n)$ are not of the same type. For example, there are cost attributes (the 
smaller the attribute values, the better) and benefit attributes (the larger the attribute values, the better), which are also known as negative attributes and positive attributes, respectively [46]. In many cases, we are interested in negative or cost attributes of alternatives, which have great impact on decision results. In this case, we should take the normalization processing measures on the attribute values and transform the attribute values of cost benefit into that of benefit attribute. Based on all of the above, the hesitant fuzzy decision matrices $D_{k}=\left(h_{i j}^{k}\right)_{m \times n}$ $(i=1,2, \cdots, m, j=1,2, \cdots, n, k=1,2, \cdots, \phi)$ can be transformed into the following matrices:

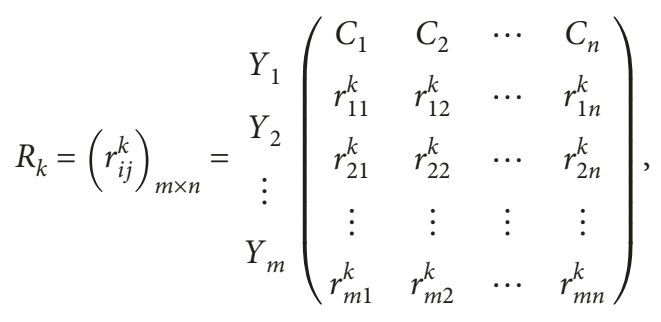

where

$$
r_{i j}^{k}= \begin{cases}h_{i j}^{k} & \text { for benefit attribute } C_{j}, \\ \left(h_{i j}^{k}\right)^{c} & \text { for cost attribute } C_{j}, \quad j=1,2, \ldots, n, k=1,2, \ldots, \phi .\end{cases}
$$

\subsection{Water-Filling Theory-Based Method for Determining} the Attribute Weights. In the multiple-attribute decision making, attribute weight is one of the main factors affecting decision results and thus is important for the decision process. In this section, considering that there are various types of decision attributes and the dimensions of decision attributes are not unified, we propose a novel approach based on the water-filling theory to determine the attribute weights. The water-filling theory was originally used to solve the problem of power optimization allocation in the field of wireless communications [47]. It is based on the signal to noise ratio (SNR) of each subchannel for adaptive transmit power allocation and is aimed at maximizing channel capacity. The lower the SNR of each subchannel is, the smaller the assigned power is, and vice versa. The main idea of the water-filling theory is illustrated in Figure 3.

When pouring water into a container with uneven bottom, it can be found that the height of the raised part changes inversely with the water content, which implies that the assigned power is small when the SNR of the subchannel is low. It can be described by the following formula:

$$
T=\sum_{j=1}^{n} \log _{2}\left(1+\frac{\alpha_{j}^{2} P_{j}}{\sigma_{j}^{2}}\right)
$$

where $T$ represents channel capacity. $\alpha_{j}, P_{j}$, and $\sigma_{j}$ represent the gain, assigned power, and noise variance of the $j$ th

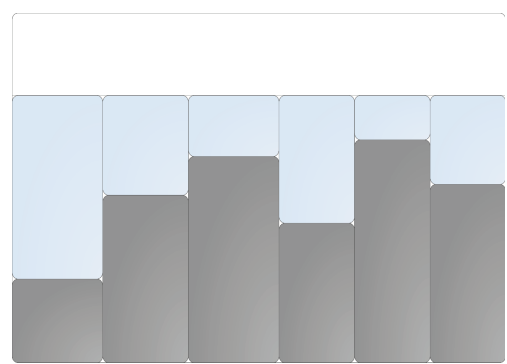

Figure 3: The schematic diagram of the water-filling theory.

subchannel, respectively. If we compare each attribute to each subchannel, then the attribute weight can be viewed as the assigned power of each subchannel [48]. The waterfilling theory can be used to convert the attribute values into a compatible scale; that is, it will eliminate the influence of dimensions so that the decision data have same caliber.

To determine the attribute weights, we will construct an optimization model based on the water-filling theory in this section. Then, the attribute weights can be obtained by solving the model. Before that, we extend the application of the water-filling theory to the hesitant fuzzy multipleattribute decision making problem. Accordingly, based on (12), an approach for determining the attribute weights under a hesitant fuzzy environment can be derived.

Definition 8. Let $w_{j}$ be the weight of the $j$ th attribute $C_{j}$, such that $\sum_{j=1}^{n} w_{j}=1$ and $w_{j} \in[0,1], j=1,2, \ldots, n$, then

$$
T_{w}=\sum_{j=1}^{n} \log _{2}\left[1+\left(\frac{s\left(C_{j}\right)}{\sigma\left(C_{j}\right)}\right)^{2} w_{j}\right]
$$

is called the total capacity of attributes. Here, $s\left(C_{j}\right)$ and $\sigma\left(C_{j}\right)$ represent the mean and standard deviation of attribute $C_{j}$, which can be calculated by (4) and (5), respectively. $T_{w}$ denotes the total capacity of attributes, which can be used to measure the information quantity of an attribute. In general, a higher value of $T_{w}$ indicates a larger information quantity of an attribute, and thus the attribute should be assigned a greater weight.

Based on the above analysis, we construct a mathematical model to determine the attribute weights under a hesitant fuzzy environment as follows:

$$
\left\{\begin{array}{l}
\max \quad T_{w}=\sum_{j=1}^{n} \log _{2}\left[1+\left(\frac{s\left(C_{j}\right)}{\sigma\left(C_{j}\right)}\right)^{2} w_{j}\right] \\
\text { s.t. } \quad \sum_{j=1}^{n} w_{j}=1, \quad 0 \leq w_{j} \leq 1 .
\end{array}\right.
$$


In order to solve the above model, we construct a Lagrange function as follows:

$$
L(\xi, w)=\sum_{j=1}^{n} \log _{2}\left[1+\left(\frac{s\left(C_{j}\right)}{\sigma\left(C_{j}\right)}\right)^{2} w_{j}\right]+\xi\left(\sum_{j=1}^{n} w_{j}-1\right)
$$

where $\xi$ denotes the Lagrange multiplier, and it is a real number.

Differentiating (15) with respect to $\xi$ and $w_{j}(j=1$, $2, \cdots, n)$, and setting them equal to zero, we can obtain the equations below:

$$
\left\{\begin{array}{l}
\frac{\partial L}{\partial w_{j}}=\frac{1}{\ln 2 \cdot\left(1+\left(s\left(C_{j}\right) / \sigma\left(C_{j}\right)\right)^{2} w_{j}\right)}\left(\frac{s\left(C_{j}\right)}{\sigma\left(C_{j}\right)}\right)^{2}+\xi=0 \\
\frac{\partial L}{\partial \xi}=\sum_{j=1}^{n} w_{j}-1=0 .
\end{array}\right.
$$

Solving (16), we can obtain the attribute weights as follows:

$$
w_{j}=\frac{1}{n}\left[1+\sum_{j=1}^{n}\left(\frac{\sigma\left(C_{j}\right)}{s\left(C_{j}\right)}\right)^{2}\right]-\left(\frac{\sigma\left(C_{j}\right)}{s\left(C_{j}\right)}\right)^{2} \quad(j=1,2, \cdots, n) .
$$

Here, $\sigma\left(C_{j}\right) / s\left(C_{j}\right)$ denotes the coefficient of variation of attribute $C_{j}[45,49]$, which can remove the impact of attribute dimension and magnitude and convert the attribute values into a compatible scale. It is a dimensionless number that can quantify the degree of variability relative to the mean. The approach can be especially effective when making a comparison between data sets with different means or units. Since the dimensions of decision attributes are not unified, a direct calculation and comparison of attribute values are not reasonable. Therefore, it is necessary to carry out the dimensionless treatment for attribute values. This is easily accomplished by the proposed model. By (17), nondimensional treatment for attribute values is produced, and thus more objective and reasonable attribute weights can be obtained.

\subsection{Regret Theory-Based Method for Hesitant Fuzzy Multiple Attribute Decision Making}

3.3.1. Hesitant Fuzzy Group Satisfaction Degree. When making decisions, people are usually irresolute and hesitant for one thing or another. And yet the hesitation stems from the uncertainty in assigning the membership degree of an element to a set. HFE can be used to model this situation. Due to hesitation among several different values, people find it hard to reach an agreement. Intuitively, the smaller the divergence between the decision makers is, the more consistent the opinion is, and the more satisfactory the decision results are. Here, we propose an index to measure the group satisfaction degree as follows.

Definition 7. Let $h$ be a HFE. Then,

$$
G(h)=\frac{s(h)}{1+\sigma(h)}
$$

is defined as the group satisfaction degree, where $s(h)$ and $\sigma(h)$ represent the score function and standard deviation of $\operatorname{HFE} h$, respectively.

The standard deviation $\sigma(h)$ in (18) expresses the concentrative level of decision makers' opinion. Generally, the smaller the $\sigma(h)$ is, the higher the cohesion is, while the bigger the $s\left(h_{i j}\right)$ is, the higher the group satisfaction degree $G(h)$ is. Thus, $G(h)$ can be used to measure the satisfaction degree of the decision makers and has the following features.

Proposition 1. Let $h$ be a HFE. Then,
(1) $0 \leq G(h) \leq 1$
(2) If $h=\{\gamma\}, G(h)=\gamma$
(3) $G(h) / G\left(h^{c}\right)=s(h) / s\left(h^{c}\right)$
(4) $G\left(\left(h^{c}\right)^{\lambda}\right)=G\left((\lambda h)^{c}\right), \lambda>0$
(5) $G\left(\lambda\left(h^{c}\right)\right)=G\left(\left(h^{\lambda}\right)^{c}\right), \lambda>0$
(6) $G\left(h_{1}^{c} \oplus h_{2}^{c}\right)=G\left(\left(h_{1} \otimes h_{2}\right)^{c}\right)$
(7) $G\left(h_{1}^{c} \otimes h_{2}^{c}\right)=G\left(\left(h_{1} \oplus h_{2}\right)^{c}\right)$

Proof.

(1) $0 \leq G(h)=s(h) /(1+\sigma(h)) \leq s(h) \leq 1$

(2) If $h=\{\gamma\}$, then $\sigma(h)=0$ and $s(h)=\gamma$, which imply that $G(h)=\gamma$

(3) Since $\sigma(h)=\sigma\left(h^{c}\right)$, we obtain

$$
\frac{G(h)}{G\left(h^{c}\right)}=\frac{s(h) / 1+\sigma(h)}{s\left(h^{c}\right) / 1+\sigma\left(h^{c}\right)}=\frac{s(h)}{s\left(h^{c}\right)}
$$

(4) Since $\left(h^{c}\right)^{\lambda}=\bigcup_{\gamma \in h}\left\{(1-\gamma)^{\lambda}\right\}=\left(\bigcup_{\gamma \in h}\left\{1-(1-\gamma)^{\lambda}\right\}\right)^{c}=$ $(\lambda h)^{c}$, we obtain

$$
G\left(\left(h^{c}\right)^{\lambda}\right)=G\left((\lambda h)^{c}\right)
$$

(5) Since $\lambda\left(h^{c}\right)=\bigcup_{\gamma \in h}\left\{1-(1-(1-\gamma))^{\lambda}\right\}=\bigcup_{\gamma \in h}\left\{1-\gamma^{\lambda}\right\}=$ $\left(h^{\lambda}\right)^{c}$, we obtain

$$
G\left(\lambda\left(h^{c}\right)\right)=G\left(\left(h^{\lambda}\right)^{c}\right)
$$




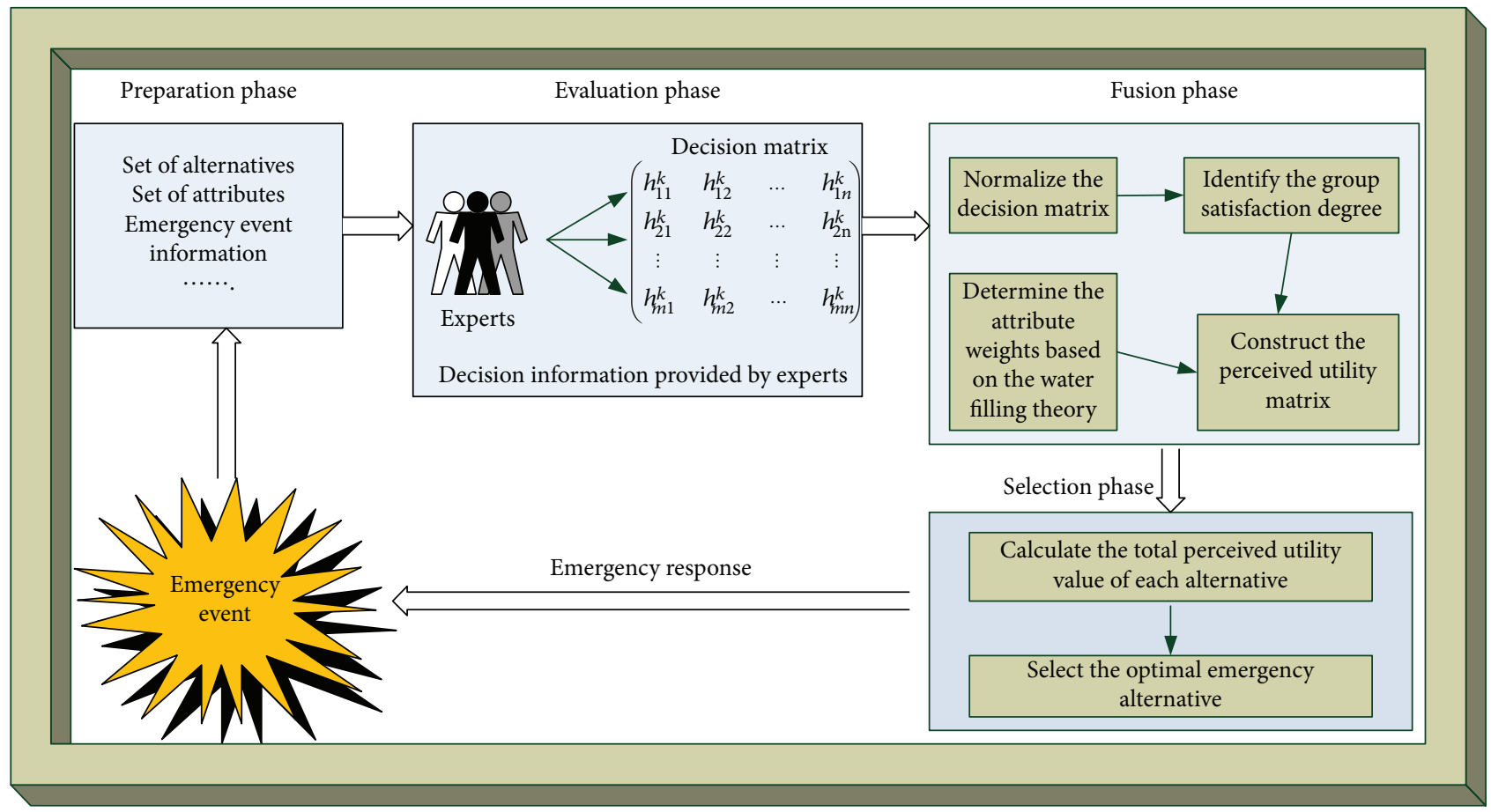

FIgURE 4: The emergency decision making process with the proposed method.

(6) Since $h_{1}^{c} \oplus h_{2}^{c}=\bigcup_{\gamma_{1} \in h_{1}, \gamma_{2} \in h_{2}}\left\{\left(1-\gamma_{1}\right)+\left(1-\gamma_{2}\right)-(1-\right.$ $\left.\left.\gamma_{1}\right)\left(1-\gamma_{2}\right)\right\}=\bigcup_{\gamma_{1} \in h_{1}, \gamma_{2} \in h_{2}}\left\{1-\gamma_{1} \gamma_{2}\right\}=\left(h_{1} \otimes h_{2}\right)^{c}$, we obtain

$$
G\left(h_{1}^{c} \oplus h_{2}^{c}\right)=G\left(\left(h_{1} \otimes h_{2}\right)^{c}\right)
$$

(7) Since $h_{1}^{c} \otimes h_{2}^{c}=\bigcup_{\gamma_{1} \in h_{1}, \gamma_{2} \in h_{2}}\left\{\left(1-\gamma_{1}\right)\left(1-\gamma_{2}\right)\right\}=\bigcup_{\gamma_{1} \in h_{1}, \gamma_{2} \in h_{2}}$ $\left\{1-\left(\gamma_{1}+\gamma_{2}-\gamma_{1} \gamma_{2}\right)\right\}=\left(h_{1} \oplus h_{2}\right)^{c}$, we obtain

$$
G\left(h_{1}^{c} \otimes h_{2}^{c}\right)=G\left(\left(h_{1} \oplus h_{2}\right)^{c}\right)
$$

Therefore, we complete the proof of the proposition.

3.3.2. Regret Theory-Based Perceived Utility Value. With the knowledge of the group satisfaction degree and regret theory, we propose an approach to hesitant fuzzy emergency decision making. First of all, the regret-rejoice value for alternative $A_{i}$ with respect to attribute $C_{j}$ can be acquired as follows:

$R_{i j}=R\left(v\left(G\left(h_{i j}\right)\right)-v\left(G\left(h_{j}^{*}\right)\right)\right), \quad i=1,2, \ldots, m, j=1,2, \ldots, n$.

Here, $R(\cdot)$ denotes the regret-rejoice function which is described in (8). $G(\cdot)$ represents the group satisfaction degree that can be calculated by (18), and $G\left(h_{j}^{*}\right)=\max _{1 \leq i \leq m}\left\{G\left(h_{i j}\right)\right\}$. Therefore, $G\left(h_{i j}\right) \leq G\left(h_{j}^{*}\right)$, which indicates $R_{i j} \leq 0$. In such case, $R_{i j}$ represents the regret value.
Then, according to (7), we can obtain the perceived utility matrix $U=\left(u_{i j}\right)_{m \times n}$, where

$$
\begin{array}{r}
u_{i j}=v\left(G\left(h_{i j}\right)\right)+R\left(v\left(G\left(h_{i j}\right)\right)-v\left(G\left(h_{j}^{*}\right)\right)\right), \\
i=1,2, \ldots, m, j=1,2, \ldots, n .
\end{array}
$$

Accordingly, the total perceived utility value for each alternative $A_{i}(i=1,2, \cdots, m)$ can be obtained as below:

$$
u_{i}=\sum_{j=1}^{n} u_{i j} w_{j}, \quad i=1,2, \ldots, m,
$$

where $w_{j}(j=1,2, \cdots, n)$ denotes the weight of the $j$ th attribute $C_{j}$. Clearly, the larger $u_{i}$ is, the better the alternative $A_{i}$ is. Thus, we can rank the alternatives according to $u_{i}$.

3.4. Decision Making Procedure under a Hesitant Fuzzy Environment. In recent years, the frequent occurrence of emergency events has caused huge losses to human society. When the events happen, one of the emergency alternatives needs to be rapidly screened and implemented. On the basis of the above analysis, a hesitant fuzzy emergency decision making method for the previously mentioned problem is summarized as follows and Figure 4 is adopted to describe the specific process of the emergency decision making method.

Step 1. In a hesitant fuzzy emergency decision making problem, some experts are invited to assess alternatives $Y_{i}(i=1,2, \cdots, m)$ under attributes 
$C_{j}(j=1,2, \cdots, n)$, where all the attribute values take the form of HFEs. Then, the hesitant fuzzy decision matrices $D_{k}=\left(h_{i j}^{k}\right)_{m \times n}(i=1,2, \cdots, m$, $j=1,2, \cdots, n, k=1,2, \cdots, \phi)$ can be constructed.

Step 2. Normalize the decision matrices $D_{k}=\left(h_{i j}^{k}\right)_{m \times n}$ $(i=1,2, \cdots, m, j=1,2, \cdots, n, k=1,2, \cdots, \phi) \quad$ to get matrices $R_{k}=\left(r_{i j}^{k}\right)_{m \times n}$ by (10) and (11), and aggregate the individual decision matrix $R^{k}=$ $\left(r_{i j}^{k}\right)_{m \times n}(i=1,2, \cdots, m, j=1,2, \cdots, n, k=1,2, \cdots$, $\phi)$ into the collective hesitant fuzzy decision matrix $R=\left(r_{i j}\right)_{m \times n}(i=1,2, \cdots, m, j=1,2, \cdots, n)$ by (2).

Step 3. Determine the attribute weights $w_{j}(j=1,2, \cdots, n)$ according to (17).

Step 4. Identify the group satisfaction degree $G\left(h_{j}^{*}\right)$ and construct the perceived utility matrix $U=$ $\left(u_{i j}\right)_{m \times n}$, where $u_{i j}$ is calculated by (25).

Step 5. Calculate the total perceived utility value $u_{i}$ for each alternative $A_{i}(i=1,2, \cdots, m)$ by $(26)$, and rank the alternatives according to $u_{i}$.

Step 6. End.

\section{Case Study}

In this section, a real case on emergency decision making is presented to illustrate the application of the proposed method. Moreover, comparisons with other methods are conducted to demonstrate the advantages of the presented method.

\subsection{Problem Description: A Fire and Explosion Accident [4].} On August 12, 2015, a fire and explosion accident happened in a hazardous chemicals warehouse at Port Group in Tianjin Binhai New Area. In the accident, 165 people had been confirmed dead and more than 700 people were admitted to hospitals. As of December 10, 2015, direct economic losses reached RMB 6866 million Yuan. There was no doubt that this accident caused huge economic losses, significant casualties, environmental pollution, and adverse social impact. Many buildings and vehicles suffered damage. Moreover, the atmospheric environment in those areas had been seriously polluted. In such cases, it is essential to provide an efficient way in emergency response for avoiding additional losses. There are three important factors in considering the requirements for emergency response:

(i) $C_{1}$ : Organize to rescue victims: once the accident has happened, effective measures should be taken to save the lives of the injured and trapped. Moreover, people on site should be evacuated as soon as possible.
TABle 1: Hesitant fuzzy decision matrix $D_{1}$.

\begin{tabular}{cccc}
\hline & $C_{1}$ & $C_{2}$ & $C_{3}$ \\
\hline$Y_{1}$ & $\{0.6,0.7\}$ & $\{0.7\}$ & $\{0.4,0.6\}$ \\
$Y_{2}$ & $\{0.6\}$ & $\{0.6,0.7\}$ & $\{0.4\}$ \\
$Y_{3}$ & $\{0.6\}$ & $\{0.5\}$ & $\{0.5,0.7\}$ \\
\hline
\end{tabular}

Table 2: Hesitant fuzzy decision matrix $D_{2}$.

\begin{tabular}{cccc}
\hline & $C_{1}$ & $C_{2}$ & $C_{3}$ \\
\hline$Y_{1}$ & $\{0.7\}$ & $\{0.5\}$ & $\{0.3,0.4,0.5\}$ \\
$Y_{2}$ & $\{0.5,0.7\}$ & $\{0.6\}$ & $\{0.3\}$ \\
$Y_{3}$ & $\{0.6,0.8\}$ & $\{0.4\}$ & $\{0.5\}$ \\
\hline
\end{tabular}

(ii) $C_{2}$ : Monitor the situation quickly: in the process of emergency rescue, the rescue teams should take actions to monitor the situation and detect the existence of hidden danger in case the situation goes badly wrong.

(iii) $C_{3}$ : Prevent other explosions: the damage caused by the explosion is serious. The explosion wave usually threatens the personal and property safety of local residents. Therefore, it is necessary to timely handle the flammable and explosive materials so as to prevent more explosions.

Suppose that there are three emergency alternatives, which are denoted by $Y_{i}(i=1,2,3)$, respectively. Two experts, who command the whole process of emergency response, are invited to assess the emergency alternatives under three aspects $C_{j}(j=1,2,3)$ as described above. To select the optimal alternative, the proposed method in this paper is adopted to deal with the emergency decision making problem.

In order to evaluate the three emergency alternatives $Y_{i}(i=1,2,3)$, the following steps are involved:

Step 1. Two experts are invited to assess the three emergency alternatives $Y_{i}(i=1,2,3,4)$ with respect to three attributes $C_{j}(j=1,2,3)$, and the decision matrices $D_{k}(k=1,2)$ are constructed as shown in Tables 1 and 2 .

Step 2. $C_{j}(j=1,2,3)$ are benefit attributes. By (2), we aggregate the individual decision matrix $D_{k}(k=$ $1,2)$ into the collective hesitant fuzzy decision matrix $D$ as described in Table 3. Suppose that the two experts have the same weights.

Step 3. According to (17), the attribute weights $w_{j}(j=$ $1,2,3)$ can be obtained as below:

$$
\begin{aligned}
& w_{1}=0.3496, \\
& w_{2}=0.3322, \\
& w_{3}=0.3182 .
\end{aligned}
$$


Table 3: The collective hesitant fuzzy decision matrix $D$.

\begin{tabular}{lccc}
\hline & $C_{1}$ & $C_{2}$ & $C_{3}$ \\
\hline$Y_{1}$ & $\{0.6536,0.7000\}$ & $\{0.6127\}$ & $\{0.3519,0.4000,0.4523,0.4708,0.5101,0.5528\}$ \\
$Y_{2}$ & $\{0.5528,0.6536\}$ & $\{0.5999,0.6536\}$ & $\{0.3519\}$ \\
$Y_{3}$ & $\{0.5999,0.7171\}$ & $\{0.4523\}$ & $\{0.5000,0.6127\}$ \\
\hline
\end{tabular}

Step 4. The group satisfaction degree matrix $G=\left(g_{i j}\right)_{3 \times 3}$ can be obtained, where $g_{i j}$ is calculated by (18).

$$
G=\left[\begin{array}{lll}
0.6553 & 0.6127 & 0.4253 \\
0.5631 & 0.6039 & 0.3519 \\
0.6081 & 0.4523 & 0.5153
\end{array}\right] .
$$

Identify the group satisfaction degree $G\left(h_{j}^{*}\right)$ and construct the perceived utility matrix $U=$ $\left(u_{i j}\right)_{m \times n}$, where $u_{i j}$ is calculated by (25). We set $\alpha=0.88$ as in Tversky and Kahneman [3] (which used experimental verifications). Assume that $\delta=0.3[19,20]$.

$$
U=\left[\begin{array}{lll}
0.6894 & 0.6498 & 0.4449 \\
0.5771 & 0.6391 & 0.3500 \\
0.6322 & 0.4507 & 0.5580
\end{array}\right] .
$$

Step 5. Calculate the total perceived utility value $u_{i}$ for each alternative $Y_{i}(i=1,2,3)$ by $(26)$, then

$$
\begin{aligned}
& u_{1}=0.5984, \\
& u_{2}=0.5254, \\
& u_{3}=0.5483,
\end{aligned}
$$

which implies that $Y_{1}>Y_{3}>Y_{2}$. Here, " $>$ " denotes "prior to." Therefore, $Y_{1}$ is the optimal emergency alternative.

4.2. Comparative Analysis. In this section, a comparison with two different types of decision making methods is given to demonstrate the validity and feasibility of the proposed method. The first type of method is based on bounded rationality, and the second type of method is based on complete rationality.

4.2.1. Comparison with the Method Based on Prospect Theory. The emergency decision making problem above was also studied by Ren et al. [4]. They proposed a thermodynamic method based on the prospect theory to deal with the emergency decision making problem. The two experts were assumed to have the same weights. The hesitant fuzzy preference relations were provided by the two experts as follows:

$$
P_{1}=P_{2}=\left[\begin{array}{lll}
\{0.5\} & \{0.6\} & \{0.6\} \\
\{0.4\} & \{0.5\} & \{0.5\} \\
\{0.4\} & \{0.5\} & \{0.5\}
\end{array}\right] \text {. }
$$

Moreover, the expectation level of each aspect with respect to each criterion of each expert was assumed to be as below:

$$
\begin{aligned}
& L^{1}=\left(\begin{array}{lll}
0.5, & 0.6, & 0.4
\end{array}\right) \\
& L^{2}=\left(\begin{array}{lll}
0.6, & 0.4, & 0.4
\end{array}\right) .
\end{aligned}
$$

They adopted the method in $\mathrm{Xu}$ et al. [39] to obtain the priority vector of the attributes

$$
W^{1}=W^{2}=\left(\begin{array}{lll}
0.4, & 0.3, & 0.3
\end{array}\right)^{T} .
$$

Then, the corresponding hesitant fuzzy prospect decision matrices were constructed. After this step, the hesitant fuzzy energy matrix, the quality matrix, and the hesitant fuzzy exergy matrix for each expert were obtained. According to the hesitant fuzzy entropy of each emergency alternative, the ranking can be obtained as follows: $Y_{2}>Y_{1}>Y_{3}$. Therefore, $Y_{2}$ is the optimal alternative for the emergency decision making problem, which is obviously different from that obtained by the proposed method. The main difference between the two methods lies in the following aspects: firstly, different decision making methods may result in different outcomes. Both two methods take the decision makers' psychological behavior into account. However, the method proposed by Ren et al. [4], which is based on the prospect theory, requires the decision makers to give reference points. The decision may be changed with the variation of the selected reference points [50]. The proposed method in this paper, which is based on the regret theory, can avoid the subjective randomness caused by the artificially given reference points. Moreover, compared with the regret theory, the calculation formula of the prospect theory involves more parameters, which makes the decision making more complicated. Secondly, the priority vector of the attribute is obtained using the method in $\mathrm{Xu}$ et al. [39]. It requires the experts to compare the attributes in pairs. Then, the hesitant fuzzy preference relations can be acquired, from which the priority vector of the attributes is derived. However, there are different types of attributes. Since the physical dimensions of different attributes are different, direct comparison 
Table 4: Hesitant fuzzy decision matrix $\tilde{D}$.

\begin{tabular}{cccc}
\hline & $C_{1}$ & $C_{2}$ & $C_{3}$ \\
\hline$Y_{1}$ & $\{0.6536,0.6536,0.6536,0.6536$, & $\{0.6127,0.6127,0.6127,0.6127$, & $\{0.3519,0.4000,0.4523,0.4708$, \\
& $0.6536,0.7000\}$ & $0.6127,0.6127\}$ & $0.5101,0.5528\}$ \\
$Y_{2}$ & $\{0.5528,0.5528,0.5528,0.5528$, & $\{0.5999,0.5999,0.5999,0.5999$, & $\{0.3519,0.3519,0.3519,0.3519$, \\
& $0.5528,0.6536\}$ & $0.5999,0.6536\}$ & $0.3519,0.3519\}$ \\
$Y_{3}$ & $\{0.5999,0.5999,0.5999,0.5999$, & $\{0.4523,0.4523,0.4523,0.4523$, & $\{0.5000,0.5000,0.5000,0.5000$, \\
& $0.5999,0.7171\}$ & $0.4523,0.4523\}$ & $0.5000,0.6127\}$ \\
\hline
\end{tabular}

of the attributes is not reasonable and the attribute values should be converted into a compatible scale. In this paper, we utilize the water-filling theory to determine the attribute weights, which can remove the impact of attribute dimension and magnitude and convert the attribute values into a compatible scale. Therefore, more objective and reasonable weights of the attributes can be gotten.

4.2.2. Comparison with the Method Based on TOPSIS. Xu and Zhang [51] presented an approach based on TOPSIS to hesitant fuzzy multiple attribute decision making. The maximizing deviation method is adopted to determine the attribute weights. First, by (2), we aggregate the individual decision matrix $D_{k}(k=1,2)$ into the collective hesitant fuzzy decision matrix $D$ as in Table 3 . According to $\mathrm{Xu}$ and Zhang [51], the shorter HFE would be extended by adding the minimal values as listed in Table 4.

Based on the maximizing deviation method, the attribute weights can be derived in the following:

$$
\begin{aligned}
& w_{1}=0.1818 \\
& w_{2}=0.3875 \\
& w_{3}=0.4307
\end{aligned}
$$

The relative closeness coefficient of alternative $Y_{i}(i=$ $1,2,3$ ) with respect to the hesitant fuzzy positive ideal solution can be obtained as follows:

$$
\begin{aligned}
& R_{1}=0.7580, \\
& R_{2}=0.3876, \\
& R_{3}=0.5233,
\end{aligned}
$$

which implies that $Y_{1}>Y_{3}>Y_{2}$. Therefore, $Y_{1}$ is the optimal emergency alternative. The ranking of alternatives obtained by the method based on TOPSIS is the same as that obtained by the method based on the regret theory in this paper, which verifies the validity of the proposed method. However, there are several differences between the two methods. $\mathrm{Xu}$ and Zhang [51] utilized the maximizing deviation method to determine the attribute weights, which indicates that the attribute with a larger deviation value among alternatives would be assigned a larger weight. Nevertheless, in the multiple attribute decision making, there are different types of attributes, and the physical dimensions of different attributes are different. Therefore, it is necessary to convert the attribute values into a compatible scale in order to obtain the more objective weights. Compared with the maximizing deviation method, the method based on the water-filling theory in this paper can handle this situation better. On the other hand, the proposed method can depict the psychological behaviors of people, which conforms to the realities. Generally, individuals vary in their cognitive ability. When confronting the emergency events, people cannot consider their choices more rationally due to the limitation of their own conditions and environment factors. The proposed method fully considers the bounded rationality of people. It is reasonable to use it to deal with this situation, which makes it more superior to the hesitant fuzzy TOPSIS method.

Compared with the existing methods, the proposed method, which is based on the regret theory and waterfilling theory, has the following characteristics.

(1) The water-filling theory in the field of wireless communications, aiming at maximizing channel capacity, is extended to determine the attribute weights, and thus the application of water-filling theory is expanded. Especially in the case that the physical dimensions of decision attributes are different, the water-filling theory is a useful tool in converting the attribute values into a compatible scale and can be used to eliminate the impact of different attribute magnitude and dimension.

(2) The proposed method takes the psychological behavior of people into account. Compared with the approaches that are used under the assumption that the decision makers are fully rational, the proposed method can deal with the decision making problems more reasonably and is more suitable for the situations that people are bounded rational.

(3) A novel hesitant fuzzy emergency decision making method, which considers regret aversion, is presented. Compared with the prospect theory, the regret theory does not have to specify reference points in advance and fewer parameters are needed, which results in more extensive applications.

\section{Conclusions}

In today's world, the emergency events occurred more frequently with the increased human activities and the rapid economic development, which seriously threatened people's life and property. As an important part of emergency management, emergency decision making plays a 
noticeable rule in reducing losses and has attracted a lot of public attention. In this paper, we investigated the problem of hesitant fuzzy emergency decision making with unknown weight information.

It is noted that decisions are usually correlated with behaviors in the actual decision making process, and thus the psychological behaviors of people should be integrated into decision analysis. Keeping this in mind, we proposed a novel hesitant fuzzy emergency decision making method based on the regret theory. In the proposed method, the regret aversion of people is integrated into the decision process. By the water-filling theory, we construct a mathematical model to determine the attribute weights. Then the proposed method is applied to emergency decision making. The main contributions in this paper are in the following. Firstly, a new calculation formula for measuring group satisfaction degree is proposed, and then the function is introduced into the regret theory to depict the psychological behavior of people, which makes the method more applicable to actual problems. Secondly, the water-filling theory is adopted to determine the attribute weights, which can convert the attribute values into a compatible scale and thus eliminate the impact of different attribute dimensions. Thirdly, the approach to hesitant fuzzy emergency decision making proposed in this paper, which considers regret aversion, widens the application field of the water-filling theory and regret theory.

There are also some limitations in the proposed method. For example, if there are too many alternatives or attributes, a lot of calculation is needed. Nevertheless, with the help of the popular software such as MATLAB and LINGO, it is no big deal. In the future, we will pay attention to the risk decision making problem with hesitant fuzzy information, where the attribute values are random variables. The proposed method would be applied to solve the problem of hesitant fuzzy risk decision making.

\section{Data Availability}

The data used to support the findings of this study are 132\#available from the corresponding author upon request. It is also available at doi:10.1109/TCYB.2016.2638498.

\section{Conflicts of Interest}

The authors declare that there are no conflicts of interest regarding the publication of this paper.

\section{Acknowledgments}

This work was supported by the National Natural Science Foundation of China (Nos. 71601002, 71673001, and 71704001), the Humanities and Social Sciences Foundation of Ministry of Education of China (Nos. 16YJC630077 and 18YJC630249), the Foundation for Young Talents in College of Anhui Province (No. gxyqZD2018033), the major project of Humanities and Social Sciences of Ministry of Education of China (No. 16JJD840008), and
Anhui Provincial Natural Science Foundation (Nos. 1708085MG168 and 1808085QG224).

\section{References}

[1] C. Camerer, "Bounded rationality in individual decision making," Experimental Economics, vol. 1, no. 2, pp. 163183, 1998.

[2] D. Kahneman and A. Tversky, "Prospect theory: an analysis of decision under risk," Econometrica, vol. 47, no. 2, pp. $263-$ 291, 1979.

[3] A. Tversky and D. Kahneman, "Advances in prospect theory: cumulative representation of uncertainty," Journal of Risk and Uncertainty, vol. 5, no. 4, pp. 297-323, 1992.

[4] P. Ren, Z. Xu, and Z. Hao, "Hesitant fuzzy thermodynamic method for emergency decision making based on prospect theory," IEEE Transactions on Cybernetics, vol. 47, no. 9, pp. 2531-2543, 2017.

[5] L. Wang, Z. X. Zhang, and Y. M. Wang, "A prospect theorybased interval dynamic reference point method for emergency decision making," Expert Systems with Applications, vol. 42, no. 23, pp. 9379-9388, 2015.

[6] Y. Liu, Z. P. Fan, and Y. Zhang, "Risk decision analysis in emergency response: a method based on cumulative prospect theory," Computers and Operations Research, vol. 42, pp. 7582, 2014.

[7] U. Schmidt and H. Zank, "Risk aversion in cumulative prospect theory," Management Science, vol. 54, no. 1, pp. 208-216, 2008.

[8] P. Liu, F. Jin, X. Zhang, Y. Su, and M. Wang, "Research on the multi-attribute decision-making under risk with interval probability based on prospect theory and the uncertain linguistic variables," Knowledge-Based Systems, vol. 24, no. 4, pp. 554-561, 2011.

[9] M. Nwogugu, "A further critique of cumulative prospect theory and related approaches," Applied Mathematics and Computation, vol. 179, no. 2, pp. 451-465, 2006.

[10] M. Nagarajan and S. Shechter, "Prospect theory and the newsvendor problem," Management Science, vol. 60, no. 4, pp. 1057-1062, 2014.

[11] D. E. Bell, "Regret in decision making under uncertainty," Operations Research, vol. 30, no. 5, pp. 961-981, 1982.

[12] G. Loomes and R. Sugden, "Regret theory: an alternative theory of rational choice under uncertainty," Economic Journal, vol. 92, no. 368, pp. 805-824, 1982.

[13] J. Quiggin, "Regret theory with general choice sets," Journal of Risk and Uncertainty, vol. 8, no. 2, pp. 153-165, 1994.

[14] S. J. Humphrey, "Feedback-conditional regret theory and testing regret-aversion in risky choice," Journal of Economic Psychology, vol. 25, no. 6, pp. 839-857, 2004.

[15] H. Bleichrodt, A. Cillo, and E. Diecidue, "A quantitative measurement of regret theory," Management Science, vol. 56, no. 1, pp. 161-175, 2010.

[16] S. Michenaud and B. Solnik, "Applying regret theory to investment choices: currency hedging decisions," Journal of International Money and Finance, vol. 27, no. 5, pp. 677694, 2008.

[17] X. Li, B. Shou, and Z. Qin, “An expected regret minimization portfolio selection model," European Journal of Operational Research, vol. 218, no. 2, pp. 484-492, 2012. 
[18] K. P. Wong, "Regret theory and the competitive firm," Economic Modelling, vol. 36, pp. 172-175, 2014.

[19] X. Zhang, Z. P. Fan, and F. D. Chen, "Method for risky multiple attribute decision making based on regret theory," Systems Engineering-Theory \& Practice, vol. 33, no. 9, pp. 2313-2320, 2013.

[20] S. Zhang, J. Zhu, X. Liu, and Y. Chen, "Regret theory-based group decision-making with multidimensional preference and incomplete weight information," Information Fusion, vol. 31, pp. 1-13, 2016.

[21] Y. Lin, Y. M. Wang, and S. Q. Chen, "Hesitant fuzzy multiattribute matching decision making based on regret theory with uncertain weights," International Journal of Fuzzy Systems, vol. 19, no. 4, pp. 955-966, 2017.

[22] H. Zhou, J. Q. Wang, and H. Y. Zhang, "Grey stochastic multicriteria decision-making based on regret theory and TOPSIS," International Journal of Machine Learning and Cybernetics, vol. 8, no. 2, pp. 651-664, 2017.

[23] Y. Yang and J. Q. Wang, "SMAA-based model for decision aiding using regret theory in discrete Z-number context," Applied Soft Computing, vol. 65, pp. 590-602, 2018.

[24] S. Dadras, H. R. Momeni, and V. J. Majd, "Fuzzy surface-based control for uncertain unified chaotic systems," in 2008 International Conference on Control, Automation and Systems, pp. 608-613, Seoul, South Korea, 2008.

[25] L. A. Zadeh, "Fuzzy sets," Information and Control, vol. 8, no. 3, pp. 338-353, 1965.

[26] V. Torra, "Hesitant fuzzy sets," International Journal of Intelligent Systems, vol. 25, pp. 529-539, 2010.

[27] J. C. R. Alcantud and V. Torra, "Decomposition theorems and extension principles for hesitant fuzzy sets," Information Fusion, vol. 41, pp. 48-56, 2018.

[28] J. Gao, Z. Xu, and H. Liao, "A dynamic reference point method for emergency response under hesitant probabilistic fuzzy environment," International Journal of Fuzzy Systems, vol. 19, no. 5, pp. 1261-1278, 2017.

[29] H. Liao and Z. Xu, "Satisfaction degree based interactive decision making under hesitant fuzzy environment with incomplete weights," International Journal of Uncertainty, Fuzziness and Knowledge-Based Systems, vol. 22, no. 4, pp. 553-572, 2014.

[30] X. Liu, Z. Wang, and S. Zhang, "A modification on the hesitant fuzzy set lexicographical ranking method," Symmetry, vol. 8, no. 12, p. 153, 2016.

[31] X. Liu, J. Zhu, S. Zhang, J. Hao, and G. Liu, "Integrating LINMAP and TOPSIS methods for hesitant fuzzy multiple attribute decision making," Journal of Intelligent \& Fuzzy Systems, vol. 28, no. 1, pp. 257-269, 2015.

[32] F. Meng and X. Chen, "Correlation coefficients of hesitant fuzzy sets and their application based on fuzzy measures," Cognitive Computation, vol. 7, no. 4, pp. 445-463, 2015.

[33] J. J. Peng, J. Q. Wang, and X. H. Wu, "Novel multi-criteria decision-making approaches based on hesitant fuzzy sets and prospect theory," International Journal of Information Technology \& Decision Making, vol. 15, no. 3, pp. 621-643, 2016.

[34] R. M. Rodríguez, B. Bedregal, H. Bustince et al., “A position and perspective analysis of hesitant fuzzy sets on information fusion in decision making: towards high quality progress," Information Fusion, vol. 29, pp. 89-97, 2016.

[35] S. P. Wan, Y. L. Qin, and J. Y. Dong, "A hesitant fuzzy mathematical programming method for hybrid multi-criteria group decision making with hesitant fuzzy truth degrees," Knowledge-Based Systems, vol. 138, pp. 232-248, 2017.

[36] J. Q. Wang, D. D. Wang, H. Zhang, and X. H. Chen, "Multicriteria outranking approach with hesitant fuzzy sets," $O R$ Spectrum, vol. 36, no. 4, pp. 1001-1019, 2014.

[37] G. Wei, F. E. Alsaadi, T. Hayat, and A. Alsaedi, "A linear assignment method for multiple criteria decision analysis with hesitant fuzzy sets based on fuzzy measure," International Journal of Fuzzy Systems, vol. 19, no. 3, pp. 607-614, 2017.

[38] M. Xia and Z. Xu, "Hesitant fuzzy information aggregation in decision making," International Journal of Approximate Reasoning, vol. 52, no. 3, pp. 395-407, 2011.

[39] Y. Xu, L. Chen, R. M. Rodríguez, F. Herrera, and H. Wang, "Deriving the priority weights from incomplete hesitant fuzzy preference relations in group decision making," KnowledgeBased Systems, vol. 99, pp. 71-78, 2016.

[40] W. Zhou and Z. Xu, "Expected hesitant VaR for tail decision making under probabilistic hesitant fuzzy environment," Applied Soft Computing, vol. 60, pp. 297-311, 2017.

[41] B. Zhu and Z. Xu, "Analytic hierarchy process-hesitant group decision making," European Journal of Operational Research, vol. 239, no. 3, pp. 794-801, 2014.

[42] Z. X. Zhang, L. Wang, R. M. Rodríguez, Y. M. Wang, and L. Martínez, "A hesitant group emergency decision making method based on prospect theory," Complex \& Intelligent Systems, vol. 3, no. 3, pp. 177-187, 2017.

[43] B. Farhadinia, "A novel method of ranking hesitant fuzzy values for multiple attribute decision-making problems," International Journal of Intelligent Systems, vol. 28, no. 8, pp. 752-767, 2013.

[44] H. Liao, Z. Xu, and X. J. Zeng, "Novel correlation coefficients between hesitant fuzzy sets and their application in decision making," Knowledge-Based Systems, vol. 82, pp. 115127, 2015.

[45] X. Liu, Z. Wang, and A. Hetzler, "HFMADM method based on nondimensionalization and its application in the evaluation of inclusive growth," Journal of Business Economics and Management, vol. 18, no. 4, pp. 726-744, 2017.

[46] J. C. R. Alcantud and T. J. Mathew, "Separable fuzzy soft sets and decision making with positive and negative attributes," Applied Soft Computing, vol. 59, pp. 586-595, 2017.

[47] D. P. Palomar and J. R. Fonollosa, "Practical algorithms for a family of waterfilling solutions," IEEE Transactions on Signal Processing, vol. 53, no. 2, pp. 686-695, 2005.

[48] H. Zhao, A. J. Yan, and P. Wang, "On improving reliability of case-based reasoning classifier," Acta Automatica Sinica, vol. 40, no. 9, pp. 2029-2036, 2014.

[49] S. T. Liu, "A mathematical programming approach to sample coefficient of variation with interval-valued observations," TOP, vol. 24, no. 1, pp. 1-18, 2016.

[50] S. P. Wan and D. F. Li, "Fuzzy LINMAP approach to heterogeneous MADM considering comparisons of alternatives with hesitation degrees," Omega, vol. 41, no. 6, pp. 925-940, 2013.

[51] Z. Xu and X. Zhang, "Hesitant fuzzy multi-attribute decision making based on TOPSIS with incomplete weight information," Knowledge-Based Systems, vol. 52, no. 6, pp. 53-64, 2013. 


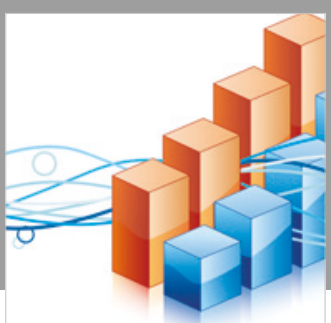

Advances in

Operations Research

\section{-n-m}
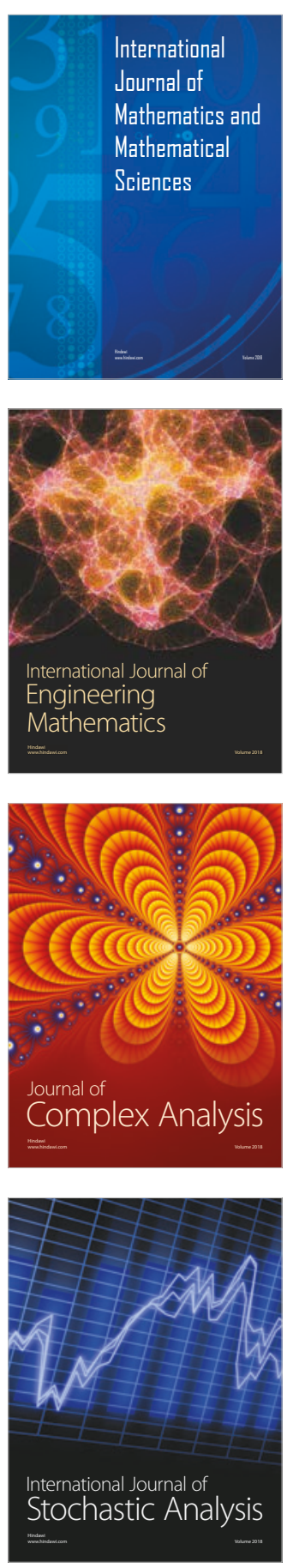
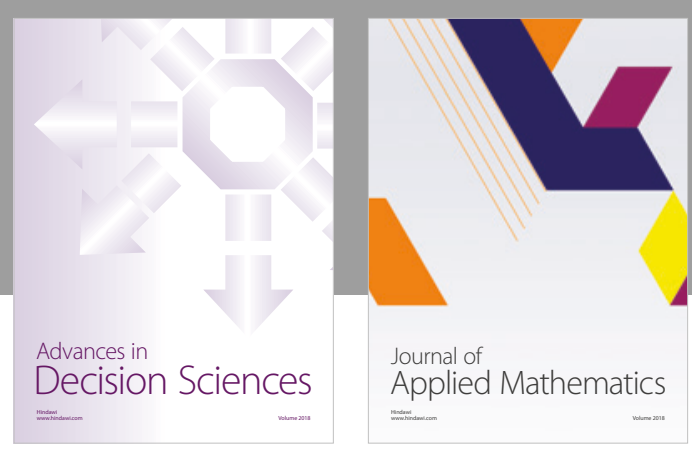

Journal of

Applied Mathematics
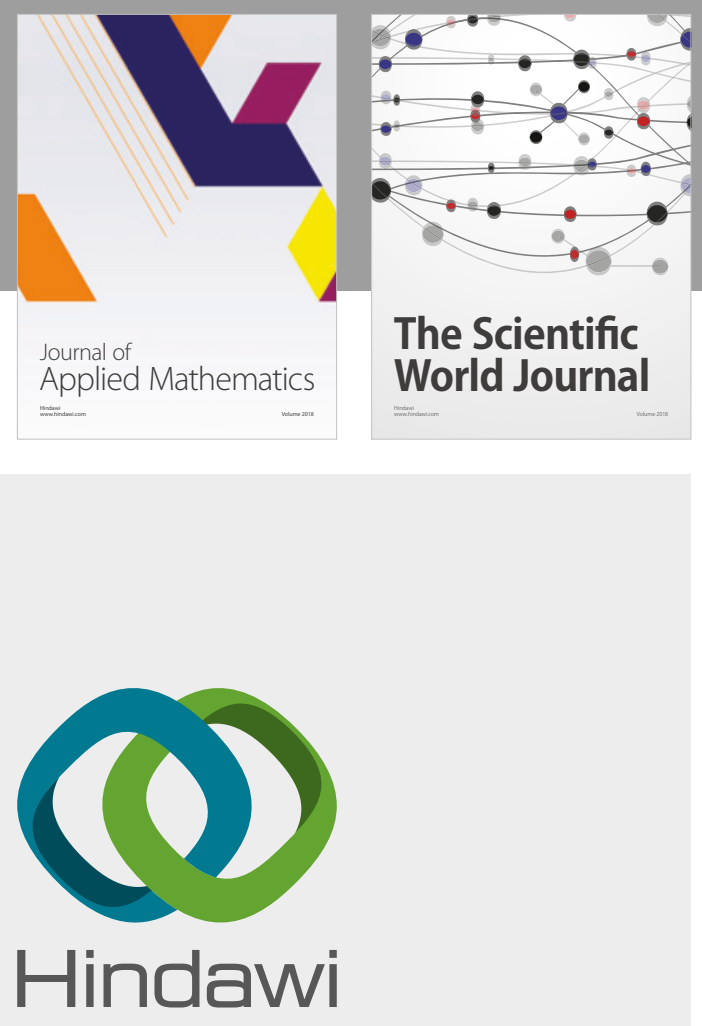

Submit your manuscripts at

www.hindawi.com

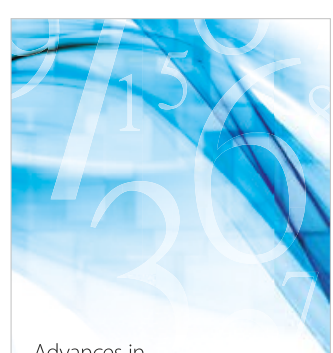

Advances in
Numerical Analysis
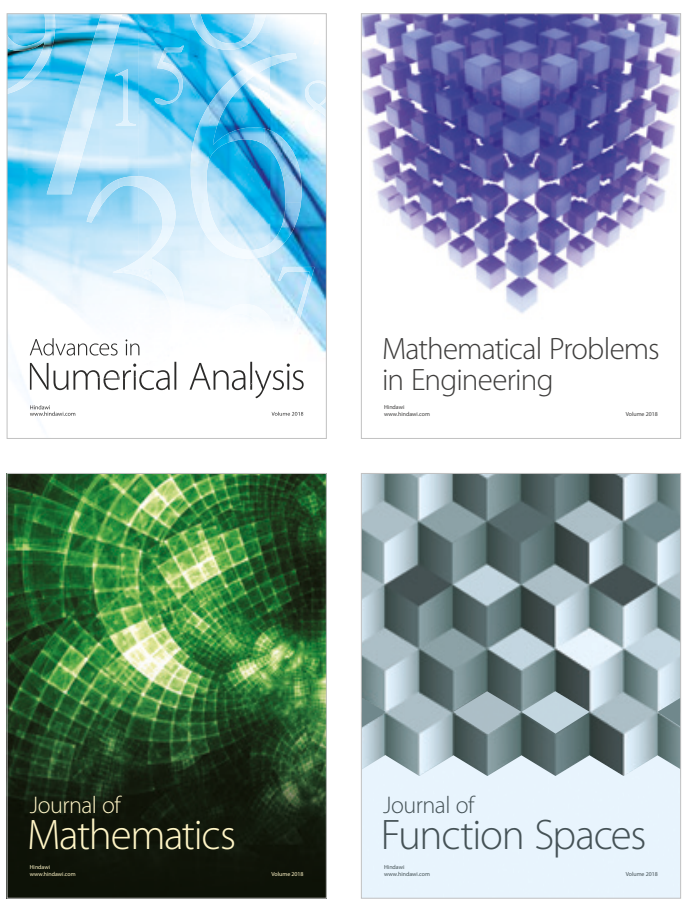

Mathematical Problems in Engineering

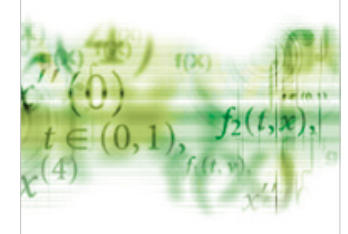

International Journal of

Differential Equations

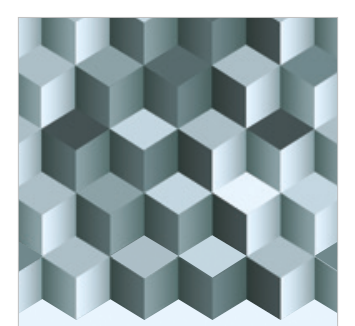

Journal of

Function Spaces
The Scientific

World Journal

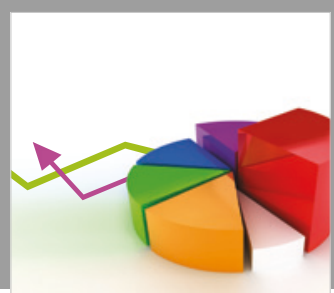

Journal of

Probability and Statistics
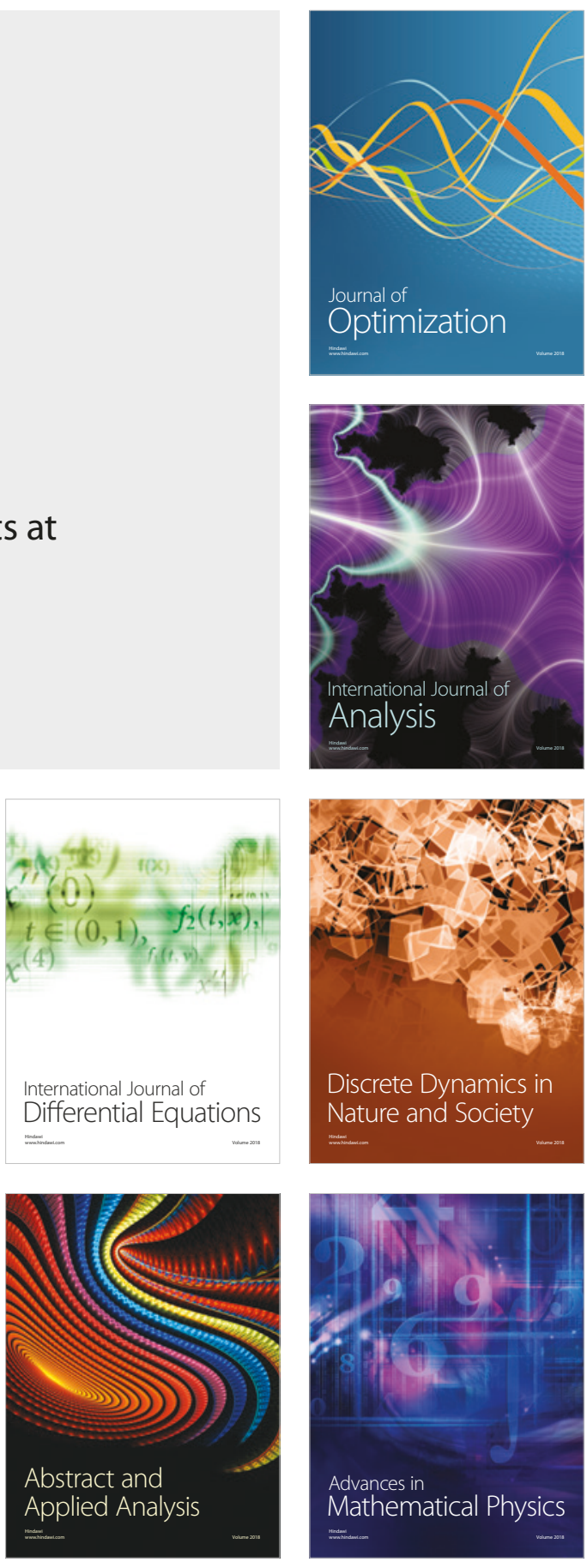